\title{
Competitive Adsorption of Heavy Metal Ions from Aqueous Solutions onto Activated Carbon and Agricultural Waste Materials
}

\author{
Xiaofeng Liu ${ }^{1}$, Xin $\mathrm{Xu}^{2}$, Xiaoqiang Dong ${ }^{1 *}$, Jounboum Park ${ }^{2 * *}$ \\ ${ }^{1}$ College of Civil Engineering, Taiyuan University of Technology, Taiyuan, China \\ ${ }^{2}$ Department of Geotechnical and Geo-Environmental Engineering, Seoul National University, Seoul, South Korea
}

Received: 17 December 2018

Accepted: 17 February 2019

\begin{abstract}
Agricultural waste materials (peanut shell and sawdust) were used as replacements for activated carbon to remove heavy metal ions from aqueous solution. Batch adsorption experiments were conducted in single, and competitive systems. The adsorption efficiencies of different heavy metal ions were, in descending order: lead, copper, cadmium. Activated carbon showed best adsorption efficiency (lead: $14.01 \mathrm{mg} / \mathrm{g}$; copper: $13.1 \mathrm{mg} / \mathrm{g}$; cadmium: $5.5 \mathrm{mg} / \mathrm{g}$ ), followed by peanut shell (lead: $9.5 \mathrm{mg} / \mathrm{g}$; copper: $49.1 \mathrm{mg} / \mathrm{g}$; cadmium: $5.07 \mathrm{mg} / \mathrm{g}$ ), and sawdust (lead: $5.5 \mathrm{mg} / \mathrm{g}$; copper: $5.3 \mathrm{mg} / \mathrm{g}$; cadmium: $3.99 \mathrm{mg} / \mathrm{g}$ ), which showed the worst efficiency. The amount of heavy metal ions adsorbed onto activated carbon, peanut shell and sawdust increased with the increase of adsorption time and then reached equilibrium values. As the initial concentration of heavy metal ions increased, the amount of heavy metal ions adsorbed increased while the removal ratios thereof decreased. The adsorption processes in both single and competitive systems followed a Langmuir isotherm model and pseudo second-order kinetic model. The intraparticular diffusion process can be divided into two stages for the adsorption process of heavy metal ions. There were antagonistic effects among three kinds of heavy metal ions in a competitive system.
\end{abstract}

Keywords: lead, copper, cadmium, peanut shell, sawdust

\section{Introduction}

Heavy metal pollution is a pressing problem: owing to the emission of industrial three waste gas, wastewater and waste residue, emission of automobile exhaust gas, sewage irrigation, use of pesticides, use of herbicide,

*e-mail: 13333515050@126.com

**e-mail: junbpark@snu.ac.kr application of chemical fertiliser, development of the mining industry, the soil, water and atmosphere are severely polluted by heavy metal ions $[1,2]$. Cadmium, lead and copper are the most common pollutant elements in wastewater and can cause significant problems [3]. Heavy metal ions in wastewater cannot be biodegraded but accumulate to either directly or indirectly threaten living beings, including humans $[4,5]$. Cadmium in the human body can cause hypertension, cardiocerebral vascular diseases, destruction of bones, liver, kidney or renal failure [6]. Lead can directly injure the human 
brain cells and especially the nervous system of a foetus (causing congenital feeblemindedness) [7]. Copper is a necessary microelement for life, but excessive copper is harmful to humans, animals and plants [8].

At present, the treatment technologies for heavy metal ions in wastewater mainly include adsorption, flocculation, precipitation, membrane separation, and biological methods [9]. Among these, adsorption is a commonly used method for wastewater treatment by using porous solid substances to adsorb pollutants from aqueous solution [10]. Activated carbon is a nonpolar adsorbent and is widely used for the adsorption of heavy metal ions from wastewater. Owing to the special pore structure and high specific surface area, it has strong adsorption capacity and offers a high removal rate for heavy metal ions; however, because of its cost, its application is limited: it is thus necessary to find alternative materials for use as adsorbents in wastewater treatment $[11,12]$. Some agricultural waste materials are potential adsorbents for heavy metal ion removal since they are cheap and always include some adsorptive constituents such as lignin and cellulose [1315]. China is an agricultural nation and thus generates significant amounts of agricultural waste. There are still 286 million tonnes of agricultural wastes that remain unused annually [16]. These were always burned for heating or discarded without any industrial utilization [17, 18]. Sawdust is produced every year in large quantities as a by-product of the woodworking process [17]. Total peanut shell production in China is also very large [19]. Therefore, the easy accessibility of peanut shells and sawdust may indicate a bright future for their application in the treatment of wastewater. Peanut shells and sawdust are cheap agricultural waste materials that can be used as potential adsorbents for heavy metal ion removal [20, 21]. Currently, many researchers have shown that peanut shells and sawdust exhibit good adsorption efficiency for heavy metal ions at a reasonable cost [22-27].

Usually, many kinds of heavy metal ions are present in wastewater at one time. There are three types of inter effects in the multicomponent system: synergism, antagonism and non-interaction [28, 29]. The adsorption efficiency in a competitive system was always lower than that in a single system because of antagonistic interaction [30]. Researchers have tried to develop novel methods for multiple heavy metal removal; however, scholars have seldom studied the competitive adsorption characteristics of heavy metal ions on peanut shells and sawdust [31-34].
The object of this research is to investigate the competition adsorption characteristics for the field application of peanut shell and sawdust in multiple heavy metal-contaminated wastewater treatments. Agricultural waste materials (peanut shell and sawdust) were selected as adsorbents, and activated carbon was selected for comparison: batch adsorption experiments using single heavy metal ion solutions and mixed heavy metal ion solutions were conducted to investigate the competitive adsorption characteristics. Adsorption equilibrium experiments were performed and adsorption kinetics were investigated. Adsorption results under different initial pollutant concentrations were used to study the adsorption isotherms. The effect of interactions among heavy metal ions in a competitive system was evaluated by evaluation ratio $E$.

\section{Methodology of Experiment}

\section{Adsorbent Preparation}

Peanut shells and activated carbon were taken from Shanxi Province, China. Sawdust was obtained from coconut trees in Hainan Province, China. All materials were washed with tap water three times to remove the coloration and dirt, then they were washed with distilled water three times. They were then oven-dried at $70^{\circ} \mathrm{C}$ for $48 \mathrm{~h}$ and pulverized. The pulverized materials were sieved with 16-mesh and 20-mesh wire material sieves to obtain the $0.85-1.18 \mathrm{~mm}$ size fraction. The adsorbents were shaken for about 10 minutes in the sieves and then stored in different bottles. The characteristics of the adsorbents are listed in Table 1.

\section{SEM and EDS of Adsorbents}

The morphology and chemical compositions of adsorbents were analyzed by scanning electron microscope (SEM) and consideration of their energy dispersion spectrum (EDS) (Fig. 1). There are many pores in the surface of activated carbon, providing high adsorption efficiency for heavy metal ions. Peanut shells have a rough, textured structure and cavities or pores on their surface, thus peanut shells can be used for adsorption. Sawdust shows anisotropic characteristics and has few pores, indicating the possibility of use in heavy metal adsorption. The main elements present therein are carbon and oxygen.

Table 1. Characteristics of adsorbents.

\begin{tabular}{|c|c|c|c|c|c|c|}
\hline Adsorbents & $\begin{array}{c}\text { Fixed carbon content } \\
(\%)\end{array}$ & $\begin{array}{c}\text { Ash content } \\
(\%)\end{array}$ & $\begin{array}{c}\text { Volatile content } \\
(\%)\end{array}$ & $\begin{array}{c}\text { Surface area } \\
\left(\mathrm{m}^{2} / \mathrm{g}\right)\end{array}$ & $\begin{array}{c}\mathrm{pH} \\
(\mathrm{yuan} / \mathrm{kg})\end{array}$ \\
\hline Peanut shell & 9 & 27 & 29 & 2.8 & 6.7 & 0 \\
\hline Sawdust & 6 & 25 & 31 & 1.01 & 5.1 & 5 \\
\hline Activated carbon & 71 & 14 & 12 & 560 & 8.3 & 15 \\
\hline
\end{tabular}


a)
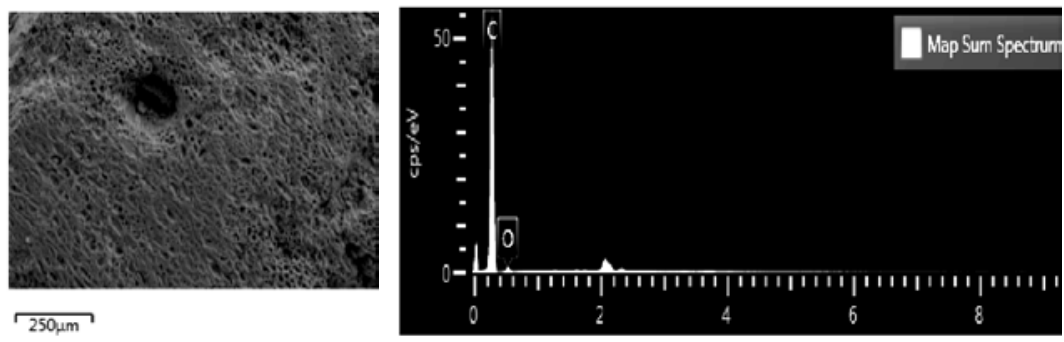

\begin{tabular}{|c|c|c|}
\hline Element & Wt.\% & At\% \\
\hline $\mathrm{C}$ & 92.21 & 94.03 \\
\hline $\mathrm{O}$ & 7.91 & 5.97 \\
\hline
\end{tabular}

b)
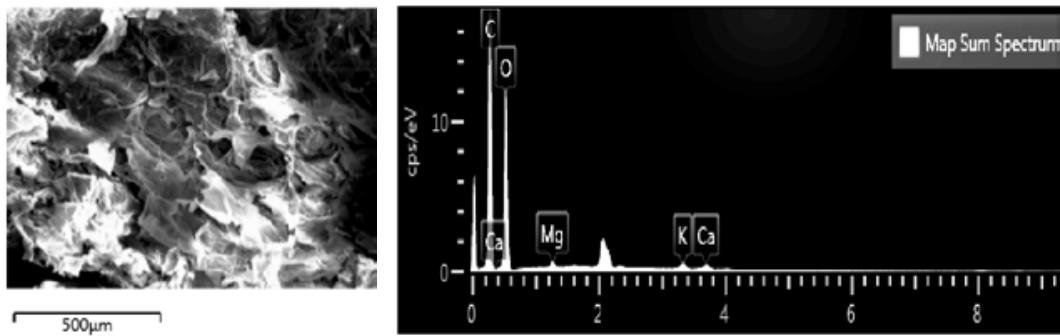

\begin{tabular}{|c|c|c|}
\hline Element & $\mathrm{Wt.} \%$ & $\mathrm{At} \%$ \\
\hline $\mathrm{C}$ & 50.09 & 57.89 \\
\hline $\mathrm{O}$ & 47.39 & 41.11 \\
\hline $\mathrm{Mg}$ & 0.53 & 0.30 \\
\hline $\mathrm{K}$ & 1.05 & 0.37 \\
\hline $\mathrm{Ca}$ & 0.94 & 0.33 \\
\hline
\end{tabular}

c)
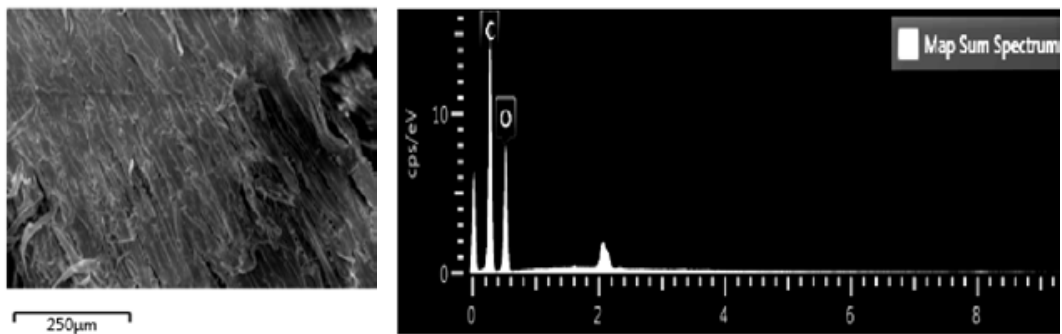

\begin{tabular}{|c|c|c|}
\hline Element & Wt.\% & At. \% \\
\hline $\mathrm{C}$ & 55.97 & 62.87 \\
\hline $\mathrm{O}$ & 44.03 & 37.13 \\
\hline
\end{tabular}

Fig. 1. SEM photographs and EDS spectra of adsorbents: a) activated carbon, b) peanut shell, c) sawdust.

\section{FTIR of Adsorbents}

At present, Fourier transform infrared spectrometry (FTIR) has become one of most useful analytical means, it can be used to detect the functional groups in adsorbents. Fig. 2 showed the FTIR results of different adsorbents, which can explain the difference between adsorbents.

Fig. 2a) was FTIR spectra of activated carbon. The broad band around $3425 \mathrm{~cm}^{-1}$ indicates the existence of hydroxyl groups with $\mathrm{O}-\mathrm{H}$ stretching vibrations. The peak at $2900 \mathrm{~cm}^{-1}$ is attributed to $\mathrm{C}-\mathrm{H}$ stretching vibrations. There are five peaks between 2000 and $1000 \mathrm{~cm}^{-1}$. The peak around $1800 \mathrm{~cm}^{-1}$ can be attributed to $\mathrm{C}=\mathrm{O}$ stretching vibration in carboxylic group. The peak around $1600 \mathrm{~cm}^{-1}$ belongs to $\mathrm{C}=\mathrm{C}$ stretching vibration absorption. The peak around 1400 belong to COO- vibration. The peak around $1000 \mathrm{~cm}^{-1}$ is $\mathrm{C}-\mathrm{O}$ stretching vibration of $\mathrm{CH}_{2}-\mathrm{O}-\mathrm{CH}_{2}$. Surface functional groups containing oxygen play an important role in the properties of activated carbon. The main functional groups in activated carbon were carboxylic group, hydroxyl group and so on, which can influence the adsorption characteristics of activated carbon [35].
Fig. 2b) was FTIR spectra of peanut shell. The peak around $3400 \mathrm{~cm}^{-1}$ can be attributed to $\mathrm{O}-\mathrm{H}$ stretching vibrations of hydroxyl groups, which can present cellulosic structure in peanut shells and are good for heavy metal ions adsorption. The peak around 2900 $\mathrm{cm}^{-1}$ is assigned to $\mathrm{C}-\mathrm{H}$ stretching vibrations of methyl groups on the surface, which indicate the existence of lignin structure [36]. The peak near $1400 \mathrm{~cm}^{-1}$ presents the $\mathrm{C}-\mathrm{O}$ stretching vibrations of the carboxyl group. The peak around $1300 \mathrm{~cm}^{-1}$ may be due to the $\mathrm{C}-\mathrm{O}, \mathrm{C}-\mathrm{H}$ or $\mathrm{C}-\mathrm{C}$ stretching vibrations. There are complex interacting vibration systems below $1000 \mathrm{~cm}^{-1}$, thus they cannot be defined as a certain vibration. From Fig. 7b), it can be concluded that there are many $\mathrm{C}-\mathrm{O}$ groups and $\mathrm{O}-\mathrm{H}$ groups in peanut shells, and these ionizable groups can interact with heavy metal ions [37].

The specific surface of sawdust is very small, thus there are no high porous structures in sawdust. The functional groups of sawdust can react with heavy metal ions in solution and form some complex, and removed heavy metal ions. The FTIR spectra of sawdust was shown in Fig. 2c). The peak around $3446 \mathrm{~cm}^{-1}$ presents $\mathrm{O}-\mathrm{H}$ stretching vibrations of hydroxyl groups. The peak around $2920 \mathrm{~cm}^{-1}$ means $\mathrm{C}-\mathrm{H}$ stretching vibrations of methylene groups. The peak around $1700 \mathrm{~cm}^{-1}$ is $\mathrm{C}=\mathrm{O}$ 

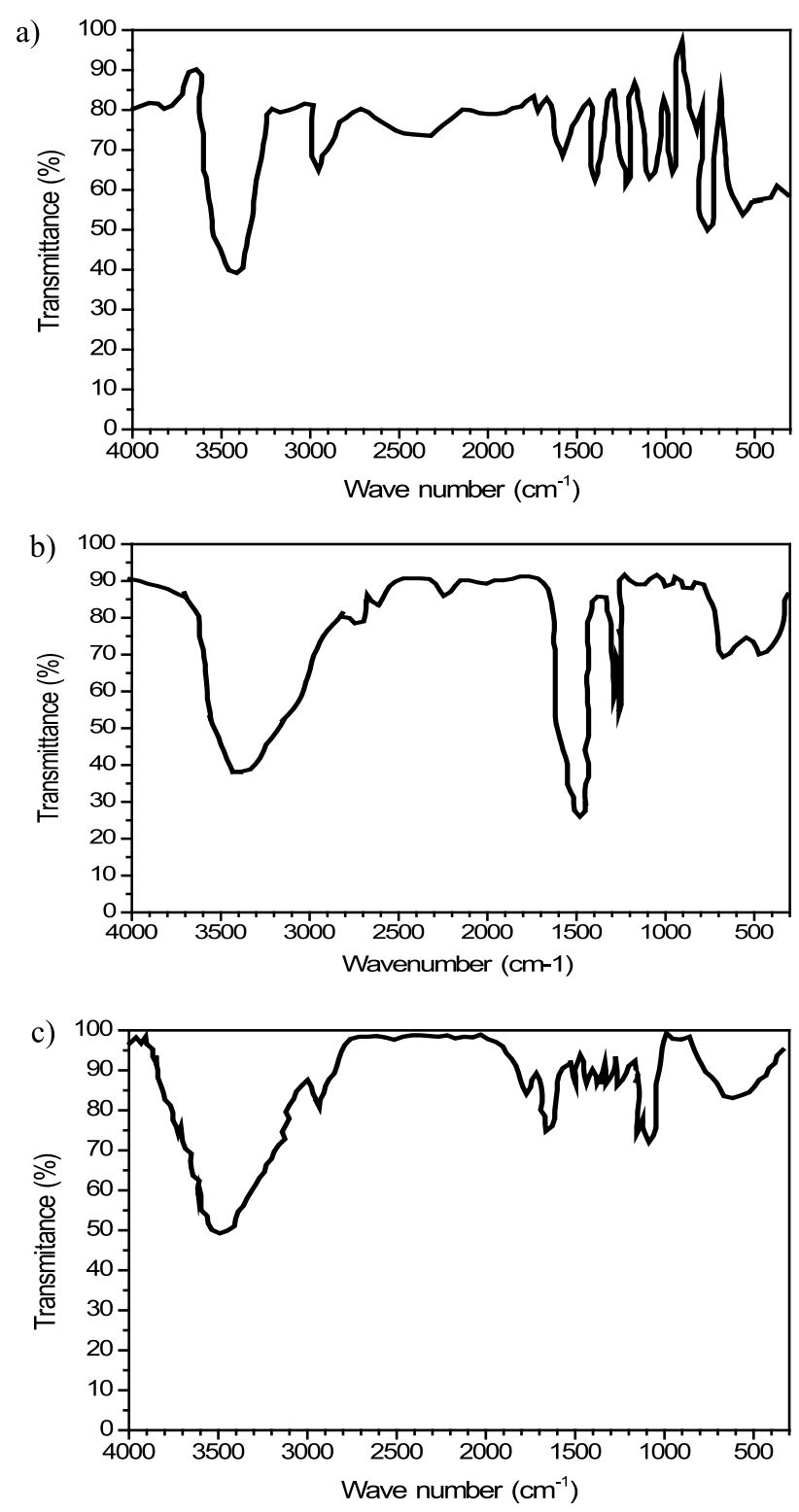

Fig. 2. FTIR spectra of adsorbents: a) activated carbon, b) peanut shell, c) sawdust.

stretching vibration of carboxyl groups. The peaks between $1500 \mathrm{~cm}^{-1}$ and $1300 \mathrm{~cm}^{-1}$ are caused by COOstretching vibrations of carboxylate functional groups, which present cellulose in sawdust. The peak between $1300 \mathrm{~cm}^{-1}$ and $1000 \mathrm{~cm}^{-1}$ can be attributed to C-O stretching vibrations of carboxylic groups. The peak around $900 \mathrm{~cm}^{-1}$ was an assignment of $\mathrm{C}-\mathrm{O}$ bending. To sum up, sawdust includes some functional groups such as carboxylic, hydroxyl and methyl. These functional groups can form complex compounds with heavy metal ions on the sawdust surface [38].

\section{Heavy Metal Solution Preparation}

Cadmium, lead, and copper ion solutions were obtained by dissolving the predefined amounts of $\mathrm{CdCl}_{2} \cdot 5 \mathrm{H}_{2} \mathrm{O} ; \mathrm{Pb}\left(\mathrm{NO}_{3}\right)_{2} ; \mathrm{Cu}\left(\mathrm{NO}_{3}\right)_{2} \cdot 2 \mathrm{H}_{2} \mathrm{O}$ in distilled water. In a single system, every kind of heavy metal compound was separately used to obtain its single solution. In a competitive system, three kinds of heavy metal compounds were mixed together. The chemical compounds were of analytical grade.

\section{Batch Scale Experiments}

A self-designed round stirrer was used for the batch adsorption experiments. To investigate the adsorption equilibrium characteristics of heavy metal ion adsorption by activated carbon, peanut shell and sawdust, batch adsorption experiments over different adsorption times were performed with other conditions fixed (room temperature: $25^{\circ} \mathrm{C}$; solution $\mathrm{pH}$ : 6.8 ; initial solution concentration: $60 \mathrm{ppm}$; adsorbent amount: $0.4 \mathrm{~g}$ ). Adsorption experiments were performed using different heavy metal concentrations ranging from 5 to $400 \mathrm{mg} / \mathrm{L}$ with other conditions fixed (room temperature: $25^{\circ} \mathrm{C}$; solution $\mathrm{pH}$ : 6.8 ; adsorption time: $5 \mathrm{~h}$; adsorbent amount: $0.4 \mathrm{~g}$ ). Each experiment was conducted in triplicate.

The solutions, after adsorption, were filtered through 0.45 um membrane filters. Then the concentrations of filtrate were measured using an atomic absorption spectrophotometer (AAS), (Analytik Jena G, DE/novAA 300).

The amount of heavy metal ions adsorbed by per unit mass of adsorbent was calculated by equation (1). The removal ratio of heavy metal ions was calculated by equation (2):

$$
\begin{gathered}
Q_{e}=\frac{\left(C_{0}-C_{e}\right) V}{M \times 1000} \\
R=\frac{\left(C_{0}-C_{e}\right)}{C_{0}} \times 100 \%
\end{gathered}
$$

...where $Q_{e}$ is the amount of heavy metal ions adsorbed by per unit mass of adsorbent at equilibrium, $\mathrm{mg} / \mathrm{g}$; $R$ is removal ratio, \%; $C_{0}$ is the initial concentration of heavy metal ions, $\mathrm{mg} / \mathrm{L} ; C_{e}$ is the concentration of heavy metal ions at equilibrium, $\mathrm{mg} / \mathrm{L} ; V$ is the volume of heavy metal solution, $\mathrm{L}$; and $M$ is the weight of the adsorbent, $\mathrm{g}$.

\section{Adsorption Kinetic Models}

Adsorption kinetics are important for the understanding of adsorption processes. The relationships between heavy metal ion adsorption and adsorption time can be used to investigate the adsorption kinetics. A pseudo first-order kinetic model, pseudo second-order kinetic model and intraparticular diffusion model were used to analyze the adsorption behaviour of heavy metal ions by activated carbon, peanut shell, and sawdust in both single and competitive systems. The linearized pseudo first-order kinetic model and pseudo secondorder kinetic model can be respectively expressed 
as equations (3) and (4) [39-41]. The intraparticular diffusion model was expressed by equation (5) [42].

$$
\begin{gathered}
\log \left(Q_{e}-Q_{t}\right)=\log Q_{e}-k_{1} t \\
\frac{t}{Q_{t}}=\frac{1}{k_{2} Q_{e}^{2}}+\frac{1}{Q_{e}} t \\
Q_{t}=k_{d} t^{1 / 2}+C
\end{gathered}
$$

...where $t$ is adsorption time, min; $Q_{t}$ is the amount of heavy metal ions adsorbed by per unit weight of adsorbent at time $t, \mathrm{mg} / \mathrm{g} ; k_{1}$ is the rate constant of pseudo first-order kinetic model, $\min ^{-1} ; k_{2}$ is the rate constant of pseudo second-order kinetic model, $\mathrm{g} /(\mathrm{mg} \cdot \mathrm{min}) ; k_{d}$ is rate constant of intraparticular diffusion, $\mathrm{mg} /\left(\mathrm{L} \cdot \mathrm{min}^{1 / 2}\right)$; and $C$ is the y-intercept, $\mathrm{mg} / \mathrm{g}$.

\section{Adsorption Isotherms}

Adsorption isotherms can help us understand the adsorption behavior: the Freundlich and Langmuir isotherms are two models used to investigate adsorption mechanisms [43]. The linear form of the Freundlich model can be expressed as equation (6). The linear form of the Langmuir model is presented as equation (7):

$$
\begin{gathered}
\log Q_{e}=\log K_{F}+\frac{1}{n} \log C_{e} \\
\frac{C_{e}}{Q_{e}}=\frac{1}{b K_{L}}+\frac{C_{e}}{b}
\end{gathered}
$$

...where $K_{F}$ is the Freundlich constant that is related to adsorption capacity of heavy metal ions by adsorbent, $\mathrm{mg} / \mathrm{g} ; n$ is Freundlich constant that can indicate the adsorption process is favorable or unfavorable; $b$ is Langmuir constant that is related to the maximum adsorption capacity of heavy metal ions by adsorbent, $\mathrm{mg} / \mathrm{g}$; and $K_{L}$ is Langmuir constant that is related to the change of adsorption energy in the adsorption process, $\mathrm{L} / \mathrm{g}$.

\section{Evaluation Ratio for Competition Adsorption}

To investigate the interactive effect of three heavy metal ions in a competitive system, an evaluation ratio was introduced, as expressed by equation (8):

$$
E=\frac{Q_{e}^{\prime}}{Q_{e}}
$$

...where $E$ is the evaluation ratio that is the ratio of $Q_{e}$ ' to $Q_{e} ; Q_{e}^{\prime}$ is the amount of heavy metal ions adsorbed in a competition system, $\mathrm{mg} / \mathrm{g}$; and $Q_{e}$ is the amount of heavy metal ions adsorbed in single system, $\mathrm{mg} / \mathrm{g}$.

\section{Results and Discussion}

\section{Adsorption Equilibrium}

The relationship between heavy metal ions adsorbed onto adsorbent and adsorption time can be used to investigate the adsorption equilibrium process. Fig. 3 shows the effect of adsorption time on the heavy metal ions amount adsorbed by activated carbon
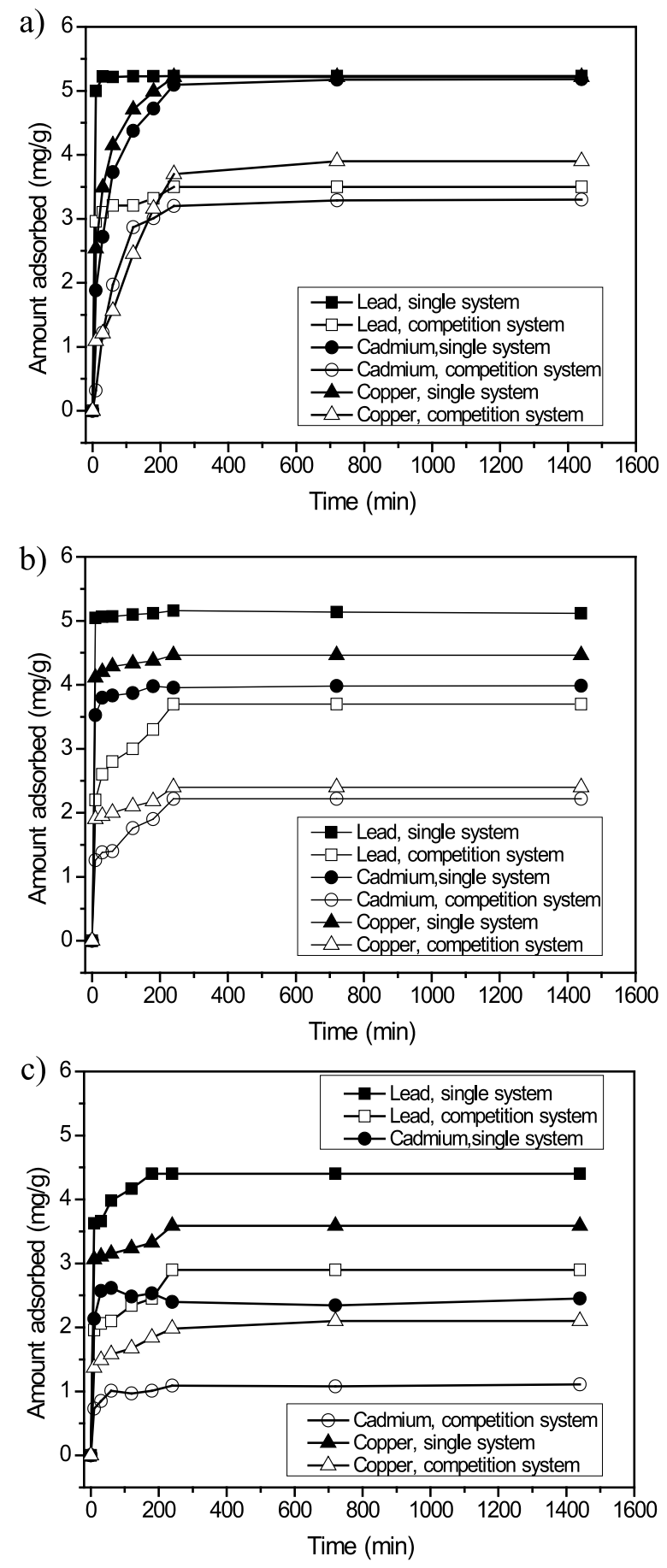

Fig. 3. Effect of adsorption time on heavy metal ions adsorbed by activated carbon, peanut shell and sawdust in single and competition systems: a) activated carbon, b) peanut shell, c) sawdust. 
(a), peanut shell (b) and sawdust (c) - in both single and competition systems. With the adsorption time increasing, the amount of heavy metal ions adsorbed increased rapidly at initial adsorption process and then increased gradually. After the increasing period, the maximum adsorption values were obtained and the adsorption process reached adsorption equilibrium. This phenomenon can be explained by the adsorption sites of adsorbents. At the beginning of the adsorption period there are enough adsorption sites on the adsorbent that were available for the heavy metal ions' adsorption [44]. With the adsorption time increasing, the adsorption sites gradually become saturated, thus slopes of curves in Fig. 3 decreased. Similar trends have been obtained by other researchers [39, 40, 43, 44].

By comparison, the adsorption capacity of three different adsorbents inferred that activated carbon showed best adsorption efficiency, followed by peanut shells, with sawdust showing the worst adsorption efficiency for three heavy metal ions. In part this was due to the high specific surface of activated carbon, and peanut shells showed higher specific surface than sawdust, even though it was not as good as activated carbon. In addition, the higher adsorption efficiency of peanut shell can be attributed to the functional groups in peanut shell.

The ascending order of three heavy metal ions adsorbed by activated carbon, peanut shell and sawdust was: lead $>$ copper $>$ cadmium. This preference of adsorbents for different kinds of heavy metal ion adsorption can be related to many reasons, the heavy metal ionic size, heavy metal ionic weight, and heavy metal ionic charge, for example [32]. These different adsorption capacities can be explained by the FTIR graphs of adsorbents.

From Fig. 3 we can see that heavy metal ions adsorption equilibrium values in a competitive system were less than those in a single system. Competition between heavy metal ions affected adsorption efficiency of every ion. The adsorption sites of the adsorbent will be replaced by other heavy metal ions in a competitive system, thus the adsorption capacity for the same heavy metal ion decreased in a competitive system [30].

\section{Adsorption Kinetics}

The pseudo first-order kinetic model was based on solution concentration, it was always used for the initial adsorption process or the adsorption period closed to equilibrium [39, 40]. The pseudo second-order kinetic model was based on the adsorption equilibrium capacity, and it was assumed that there is a proportional relationship between the adsorption capacity and the number of active sites on the surface of an adsorbent [41].

Table 2. Fitting parameters of pseudo first-order and pseudo second-order adsorption kinetic models.

\begin{tabular}{|c|c|c|c|c|c|c|c|c|}
\hline \multirow{2}{*}{$\begin{array}{l}\text { Adsorbent } \\
\text { materials }\end{array}$} & \multirow{2}{*}{ Heavy metal } & \multirow{2}{*}{ Adsorption system } & \multicolumn{3}{|c|}{ Pseudo-first-order } & \multicolumn{3}{|c|}{ Pseudo-second-order } \\
\hline & & & $k_{1}$ & $Q_{e}$ & $R^{2}$ & $k_{2}$ & $Q_{e}$ & $R^{2}$ \\
\hline \multirow{6}{*}{$\begin{array}{l}\text { Activated } \\
\text { carbon }\end{array}$} & \multirow{2}{*}{ Lead } & Singel & 0.013 & 0.22 & 0.75 & 2.73 & 5.23 & 0.99 \\
\hline & & Competition & 0.0024 & 0.49 & 0.84 & 0.18 & 3.52 & 0.99 \\
\hline & \multirow{2}{*}{ Copper } & Singel & 0.0061 & 2.75 & 0.91 & 0.088 & 5.27 & 0.99 \\
\hline & & Competition & 0.0048 & 4.03 & 0.96 & 0.017 & 4.09 & 0.99 \\
\hline & \multirow{2}{*}{ Cadmium } & Singel & 0.0037 & 2.25 & 0.92 & 0.049 & 5.27 & 0.99 \\
\hline & & Competition & 0.0062 & 2.82 & 0.96 & 0.023 & 3.43 & 0.99 \\
\hline \multirow{6}{*}{ Peanut shell } & \multirow{2}{*}{ Lead } & Singel & 0.028 & 0.11 & 0.98 & 1.39 & 5.15 & 0.99 \\
\hline & & Competition & 0.0031 & 1.48 & 0.96 & 0.063 & 3.75 & 0.99 \\
\hline & \multirow{2}{*}{ Copper } & Singel & 0.0034 & 0.32 & 0.94 & 0.46 & 4.47 & 0.99 \\
\hline & & Competition & 0.0021 & 0.53 & 0.97 & 0.10 & 2.42 & 0.99 \\
\hline & \multirow{2}{*}{ Cadmium } & Singel & 0.014 & 0.93 & 0.77 & 0.59 & 3.99 & 0.99 \\
\hline & & Competition & 0.0029 & 1.07 & 0.96 & 0.045 & 2.26 & 0.99 \\
\hline \multirow{6}{*}{ Sawdust } & \multirow{2}{*}{ Lead } & Singel & 0.0051 & 0.92 & 0.96 & 0.26 & 4.42 & 0.99 \\
\hline & & Competition & 0.0019 & 0.99 & 0.98 & 0.056 & 2.94 & 0.99 \\
\hline & \multirow{2}{*}{ Copper } & Singel & 0.0017 & 0.55 & 0.98 & 0.14 & 3.61 & 0.99 \\
\hline & & Competition & 0.0031 & 0.83 & 0.94 & 0.053 & 2.13 & 0.99 \\
\hline & \multirow{2}{*}{ Cadmium } & Singel & 0.023 & 0.99 & 0.79 & 0.085 & 2.61 & 0.99 \\
\hline & & Competition & 0.013 & 0.64 & 0.93 & 0.033 & 1.06 & 0.96 \\
\hline
\end{tabular}


The fitting parameters of pseudo first-order and pseudo second-order adsorption kinetic models are listed in Table 2. As we can see, both kinetic models can help understand the adsorption process and all the fitting degrees were in the range from 0.75 to 0.99 . The fitting degrees of the pseudo second-order kinetic model are all more than 0.96 and very close to 1 , which indicates that the heavy metal ions adsorption process fit the pseudo second-order kinetic model very well. The fitting plots of the pseudo second-order kinetic model are shown in Fig. 4.

There were always three steps for the heavy metal ions adsorption process when the adsorbent was in contact with the solution: 1) adsorbate transferred

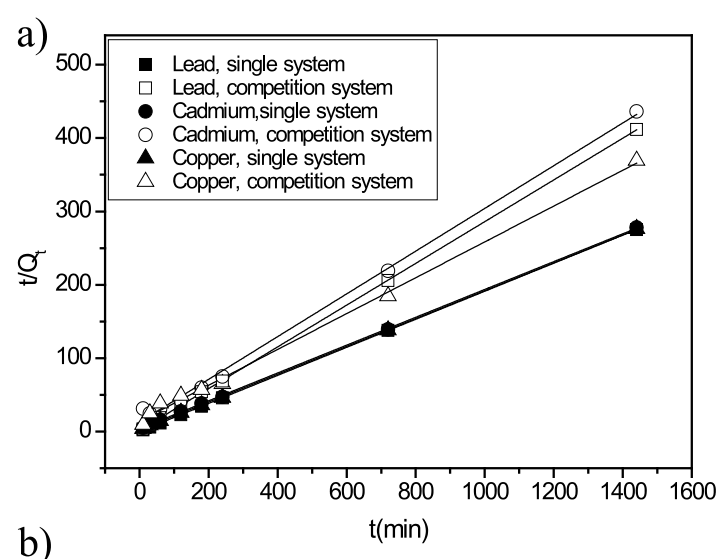

b)
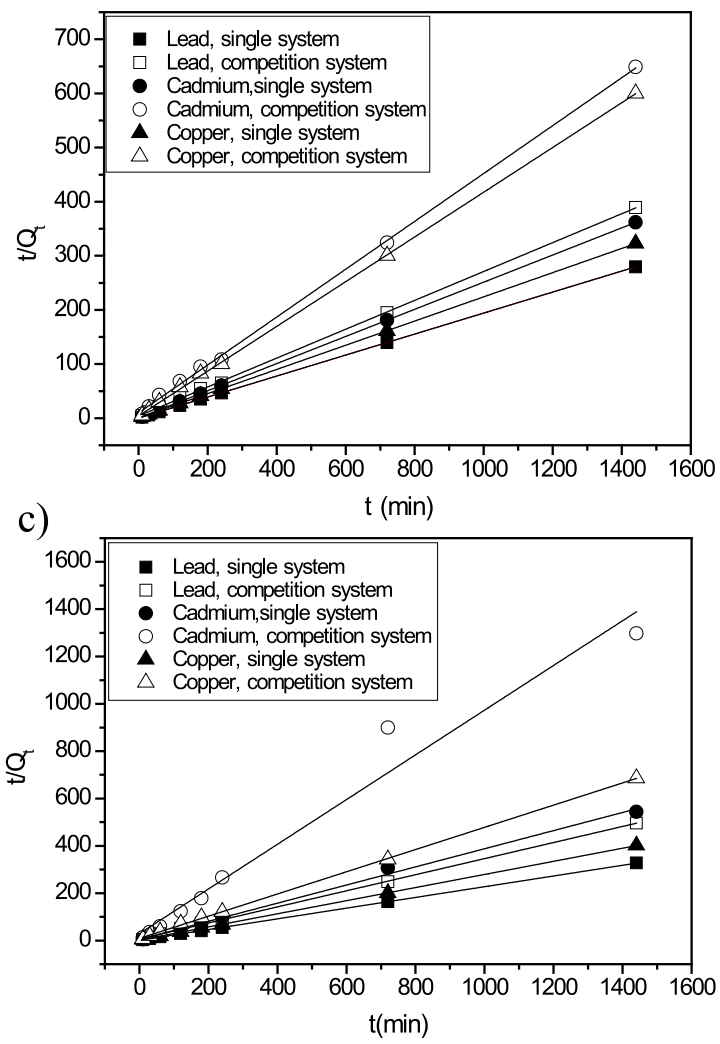

Fig. 4. Plot of linearized pseudo second-order kinetic model fitting for heavy metal ions adsorption by activated carbon, peanut shell and sawdust in single and competition systems: a) activated carbon, b) peanut shell, c) sawdust. from the bulk solution to the external boundary layer film of liquid surrounding the outside of an adsorbent particle; 2) adsorbate was attached to the surface of the adsorbent, this process was always rapid and the energy provided corresponded to the type of binding process (physical adsorption, chemical adsorption or both kinds of adsorption); and 3) adsorbate further diffused into the inner adsorption sites of the adsorbent. The heavy metal ion adsorption process, with different adsorbents, was mainly controlled by one or more steps of these three adsorption steps mentioned above [42].

Fig. 5 shows the plots of $Q_{t}$ versus $t^{1 / 2}$ for the heavy metal ions adsorption by activated carbon, peanut
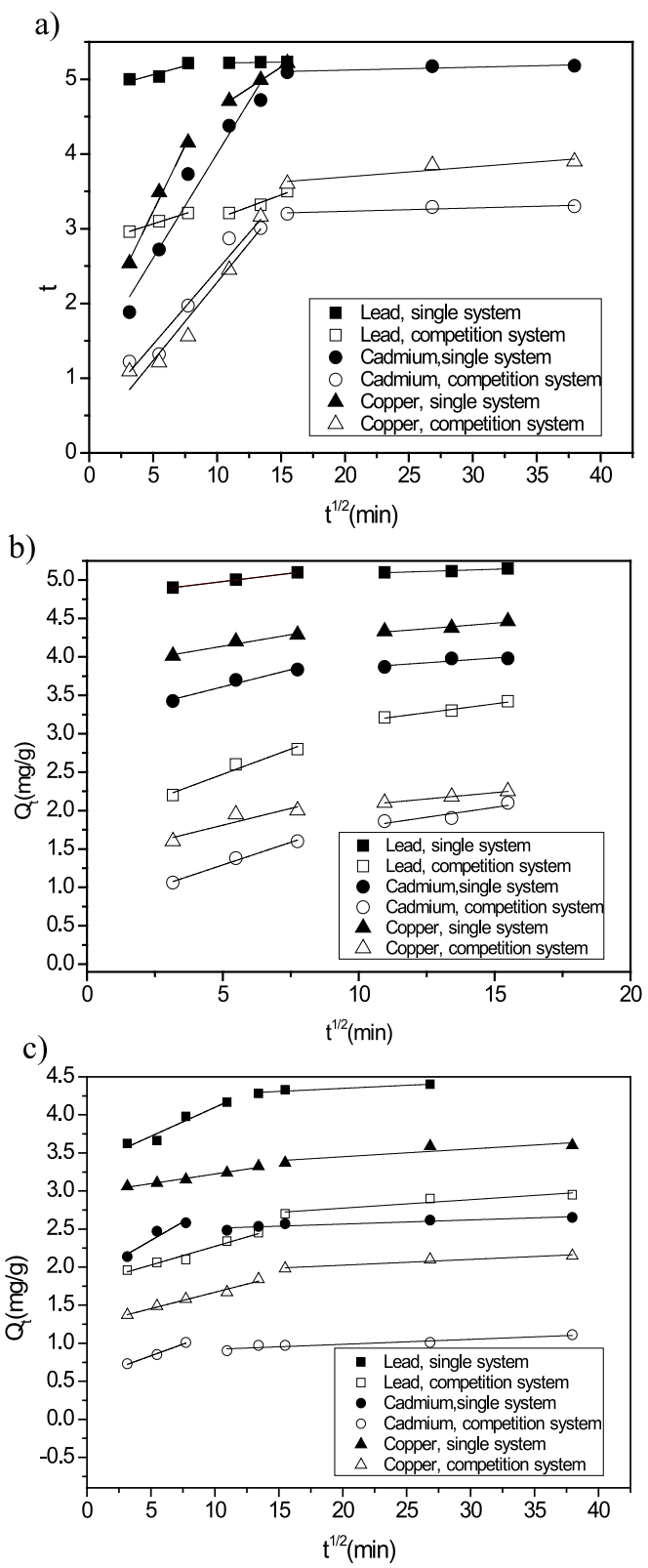

Fig. 5. Plot of intraparticular diffusion kinetic model fitting for heavy metal ion adsorption by activated carbon, peanut shell and sawdust in single and competition systems: a) activated carbon, b) peanut shell, c) sawdust. 
shell and sawdust in single and competitive systems. The adsorption processes were divided into two stages: a fast adsorption stage wherein a large amount of heavy metals were transferred from bulk solution to the external boundary layer film to be adsorbed. The intraparticular diffusion in this stage was rate limiting. The second stage was an equilibrium stage in which most adsorption was saturated, and the adsorption rate was very slow and tended to be a stable state thereafter. The rate parameters of the intraparticular diffusion model for heavy metal ion adsorption by activated carbon, peanut shell, and sawdust are listed in Table 3. The rate constants in the first stage were all higher than those in the second stage, which indicated that the intraparticular diffusion process was first rapid and then slow [42].

\section{Effect of Initial Concentration on Adsorption Efficiency}

Batch adsorption experiments were conducted under different initial concentrations. The adsorption results of different heavy metal ions by different adsorbents are shown in Fig. 6. As we can see, both in single and competition systems, with initial concentration increasing, the amount of heavy metal ions adsorbed increased, whereas the removal ratio decreased. Initial solution concentration can provide a driving force for heavy metal ions in solution to transfer from solution to the surface of adsorbent. With the increase of the initial solution concentration, the driving force is also enhanced, thus much heavier metal ions can be attached onto the adsorption sites of adsorbent. However, the adsorption sites would reach saturation state with the heavy metal ions adsorbed increasing, the changing curves of heavy metal ion amounts would turn to being stable in the late stage of concentration growth [45]. For fixed amount of adsorbents, the adsorption sites for heavy metal ions were limited, with the initial concentration increasing, the total heavy metal ions in solution also increased, corresponding to amounts of heavy metal ions that cannot be adsorbed by adsorbent also increased. As a result, the removal ratio declined with the initial concentration increasing, although the higher driving force can enhance the amount of adsorbed heavy metal ions. It can be inferred that the adsorption type is single-layer adsorption and this phenomenon can be further explained by adsorption isotherms analysis.

Table 3. Fitting parameters of intraparticular diffusion kinetic model.

\begin{tabular}{|c|c|c|c|c|c|c|c|c|}
\hline \multirow{3}{*}{ Adsorbent } & \multirow{3}{*}{ Heavy metal } & \multirow{3}{*}{ Adsorption system } & \multicolumn{6}{|c|}{ Intraparticle diffusion coefficiencies } \\
\hline & & & \multicolumn{3}{|c|}{ First stage } & \multicolumn{3}{|c|}{ Second stage } \\
\hline & & & $K_{d}$ & $C$ & $R^{2}$ & $K_{d}$ & $C$ & $R^{2}$ \\
\hline \multirow{6}{*}{ Activated carbon } & \multirow{2}{*}{ Lead } & Singel & 0.047 & 4.83 & 0.73 & 0.0026 & 5.19 & 0.87 \\
\hline & & Competition & 0.055 & 2.79 & 0.99 & 0.063 & 2.50 & 0.93 \\
\hline & \multirow{2}{*}{ Copper } & Singel & 0.35 & 1.47 & 0.98 & 0.11 & 3.48 & 0.99 \\
\hline & & Competition & 0.21 & 0.19 & 0.93 & 0.013 & 3.43 & 0.75 \\
\hline & \multirow{2}{*}{ Cadmium } & Singel & 0.28 & 1.21 & 0.94 & 0.0039 & 5.04 & 0.68 \\
\hline & & Competition & 0.20 & 0.46 & 0.93 & 0.0045 & 3.14 & 0.66 \\
\hline \multirow{6}{*}{ Peanut shell } & \multirow{2}{*}{ Lead } & Singel & 0.43 & 4.76 & 0.99 & 0.011 & 1.97 & 0.86 \\
\hline & & Competition & 0.13 & 1.82 & 0.93 & 0.046 & 2.69 & 0.96 \\
\hline & \multirow{2}{*}{ Copper } & Singel & 0.06 & 3.84 & 0.92 & 0.029 & 4.01 & 0.89 \\
\hline & & Competition & 0.087 & 1.37 & 0.69 & 0.033 & 0.74 & 0.99 \\
\hline & \multirow{2}{*}{ Cadmium } & Singel & 0.089 & 3.17 & 0.93 & 0.025 & 3.61 & 0.76 \\
\hline & & Competition & 0.12 & 0.70 & 0.98 & 0.052 & 1.27 & 0.78 \\
\hline \multirow{6}{*}{ Sawdust } & \multirow{2}{*}{ Lead } & Singel & 0.076 & 3.34 & 0.90 & 0.0080 & 4.19 & 0.84 \\
\hline & & Competition & 0.049 & 1.78 & 0.96 & 0.012 & 2.55 & 0.79 \\
\hline & \multirow{2}{*}{ Copper } & Singel & 0.025 & 2.97 & 0.98 & 0.010 & 3.24 & 0.74 \\
\hline & & Competition & 0.043 & 1.24 & 0.97 & 0.0076 & 1.87 & 0.90 \\
\hline & \multirow{2}{*}{ Cadmium } & Singel & 0.097 & 1.87 & 0.85 & 0.0054 & 2.46 & 0.83 \\
\hline & & Competition & 0.061 & 0.53 & 0.99 & 0.0065 & 0.86 & 0.88 \\
\hline
\end{tabular}


a)

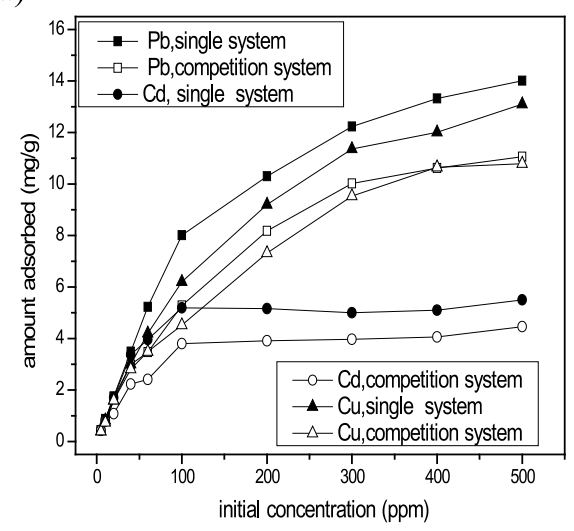

b)

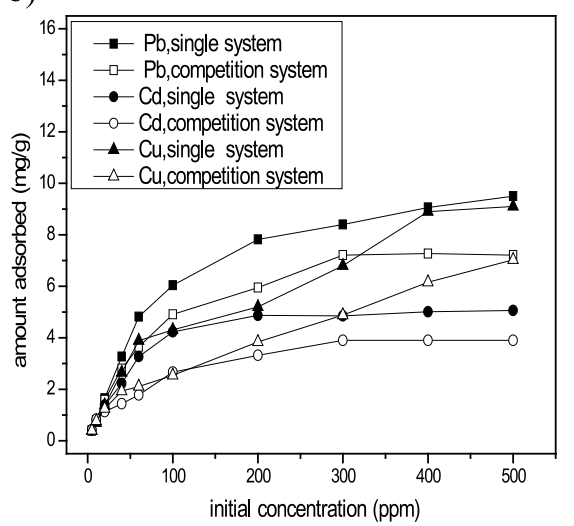

c)

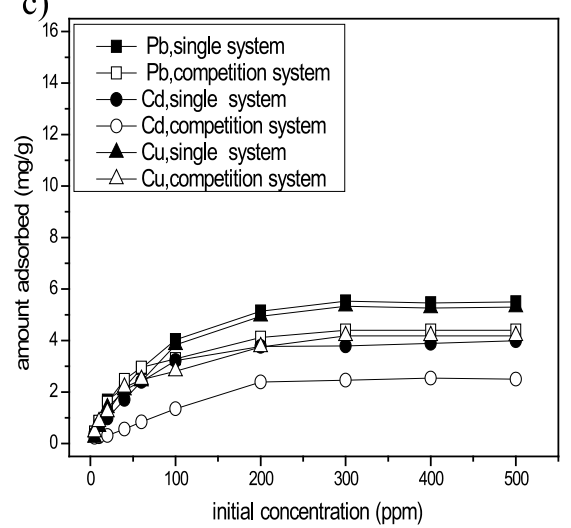

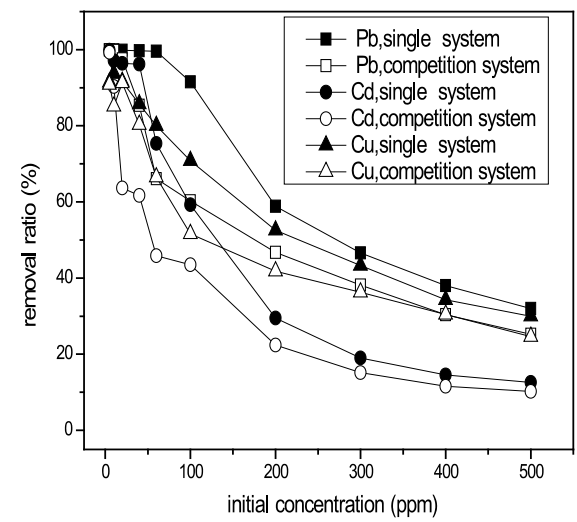
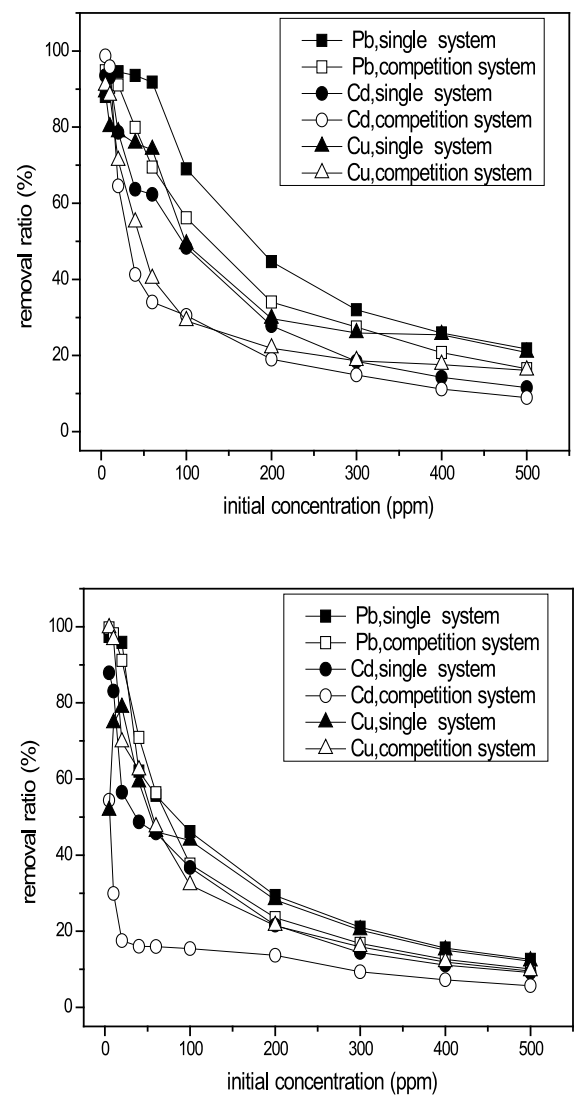

Fig. 6. Effect of initial concentrations on heavy metal ions adsorbed by activated carbon, peanut shell and sawdust in single and competition systems: a) activated carbon, b) peanut shell, c) sawdust.

\section{Adsorption Isotherms}

Adsorption results under different initial concentrations were used to fit the isotherm models. Freundlich isotherm is usually applied to characterize heterogeneous adsorption on the adsorbent surface, whereas the Langmuir isotherm was used to describe homogenous adsorption on the adsorbent surface, it was also assumed that the adsorbent surface was covered with a monolayer of adsorbates [14]. The fitting parameters of these two isotherm models are listed in Table 4. The adsorption behaviour exhibited a good fit with both isotherm models. All the $R^{2}$ values obtained from the Langmuir isotherm model were much higher than those values obtained from the use of the Freundlich isotherm model, thus it can be concluded that the adsorption behaviour of heavy metal ions by activated carbon, peanut shell, and sawdust follow the Langmuir, which assumes single-layer adsorption and is consistent with the above results (Fig. 7).

\section{Effect of Interactions among Heavy Metal Ions in a Competitive System}

$E$ can represent the type of interaction among heavy metal ions in a competitive system [46]. When $E>1$, 
Table 4. Fitting parameters of Freundlich and Langmuir isotherm models for heavy metal ions adsorption by activated carbon, peanut shell and sawdust.

\begin{tabular}{|c|c|c|c|c|c|c|c|c|}
\hline \multirow{2}{*}{ Adsorbent } & \multirow{2}{*}{ Heavy metal } & \multirow{2}{*}{ Adsorption system } & \multicolumn{3}{|c|}{ Freundlich isotherm } & \multicolumn{3}{|c|}{ Langmuir isotherm } \\
\hline & & & $K_{F}$ & $n$ & $R^{2}$ & $K_{L}$ & $b$ & $R^{2}$ \\
\hline \multirow{6}{*}{ Activated carbon } & \multirow{2}{*}{ Lead } & Single & 3.95 & 4.08 & 0.93 & 0.19 & 13.70 & 0.99 \\
\hline & & Competition & 2.10 & 3.69 & 0.98 & 0.048 & 11.35 & 0.98 \\
\hline & \multirow{2}{*}{ Copper } & Single & 1.01 & 2.10 & 0.95 & 0.044 & 13.33 & 0.99 \\
\hline & & Competition & 0.84 & 2.19 & 0.96 & 0.029 & 11.51 & 0.97 \\
\hline & \multirow{2}{*}{ Cadmium } & Single & 1.72 & 4.46 & 0.87 & 0.31 & 5.32 & 0.99 \\
\hline & & Competition & 0.93 & 3.76 & 0.94 & 0.067 & 4.40 & 0.99 \\
\hline \multirow{6}{*}{ Peanut shell } & \multirow{2}{*}{ Lead } & Single & 1.24 & 2.59 & 0.78 & 0.085 & 9.52 & 0.99 \\
\hline & & Competition & 0.97 & 2.66 & 0.95 & 0.073 & 7.46 & 0.99 \\
\hline & \multirow{2}{*}{ Copper } & Single & 0.67 & 2.19 & 0.94 & 0.027 & 9.26 & 0.94 \\
\hline & & Competition & 0.60 & 2.61 & 0.98 & 0.017 & 7.04 & 0.90 \\
\hline & \multirow{2}{*}{ Cadmium } & Single & 0.84 & 2.97 & 0.93 & 0.095 & 5.16 & 0.99 \\
\hline & & Competition & 0.84 & 3.99 & 0.96 & 0.039 & 4.12 & 0.99 \\
\hline \multirow{6}{*}{ Sawdust } & \multirow{2}{*}{ Lead } & Single & 1.15 & 3.55 & 0.93 & 0.83 & 5.65 & 0.99 \\
\hline & & Competition & 1.26 & 4.37 & 0.98 & 0.12 & 4.47 & 0.99 \\
\hline & \multirow{2}{*}{ Copper } & Single & 0.91 & 2.08 & 0.81 & 0.33 & 5.75 & 0.99 \\
\hline & & Competition & 1.06 & 4.27 & 0.98 & 0.067 & 4.32 & 0.99 \\
\hline & \multirow{2}{*}{ Cadmium } & Single & 0.55 & 2.79 & 0.95 & 0.055 & 4.12 & 0.99 \\
\hline & & Competition & 0.10 & 1.85 & 0.93 & 0.009 & 3.19 & 0.94 \\
\hline
\end{tabular}

synergism with other heavy metal ions is generated, the presence of other heavy metal ions can enhance adsorption of another heavy metal ion; when $E=1$, no interaction takes place in a competitive system, which means that the presence of other heavy metal ions would not influence the adsorption of another; each other's adsorption; and when $E<1$, antagonism prevails and the presence of another heavy metal ion would suppress the adsorption of another.

The values of $E$ for the different heavy metal ion adsorptions by activated carbon, peanut shell, and sawdust from aqueous solution with different initial solution concentrations are presented in Table 5. As mentioned, these three adsorbents show their best

Table 5. Calculated evaluation ratios.

\begin{tabular}{|c|c|c|c|c|c|c|c|c|c|c|c|}
\hline \multirow{3}{*}{ Adsorbent } & Solution concentration & 5 & 10 & 20 & 40 & 60 & 100 & 200 & 300 & 400 \\
\cline { 2 - 11 } & Heavy metal & \multicolumn{7}{|c|}{ Evaluation ratios } \\
\hline \multirow{3}{*}{ Activated carbon } & Cadmium & 0.99 & 0.93 & 0.63 & 0.66 & 0.61 & 0.73 & 0.76 & 0.79 & 0.80 \\
\cline { 2 - 12 } & Copper & 0.99 & 0.91 & 0.99 & 0.94 & 0.83 & 0.73 & 0.79 & 0.83 & 0.89 \\
\cline { 2 - 12 } & Lead & 0.97 & 0.96 & 0.98 & 0.81 & 0.66 & 0.66 & 0.79 & 0.82 & 0.80 \\
\hline \multirow{3}{*}{ Peanut shell } & Cadmium & 0.96 & 0.86 & 0.75 & 0.56 & 0.53 & 0.68 & 0.73 & 0.74 & 0.76 \\
\cline { 2 - 12 } & Copper & 0.97 & 0.98 & 0.90 & 0.73 & 0.54 & 0.61 & 0.63 & 0.63 & 0.74 \\
\cline { 2 - 11 } & Lead & 0.92 & 0.98 & 0.96 & 0.85 & 0.68 & 0.63 & 0.68 & 0.74 & 0.79 \\
\hline \multirow{3}{*}{ Sawdust } & Cadmium & 0.62 & 0.36 & 0.31 & 0.33 & 0.34 & 0.42 & 0.63 & 0.65 & 0.65 \\
\cline { 2 - 11 } & Copper & 0.87 & 0.83 & 0.87 & 0.63 & 0.65 & 0.61 & 0.78 & 0.78 & 0.81 \\
\cline { 2 - 10 } & Lead & 0.93 & 0.98 & 0.83 & 0.69 & 0.61 & 0.62 & 0.79 & 0.79 & 0.81 \\
\hline
\end{tabular}


a)

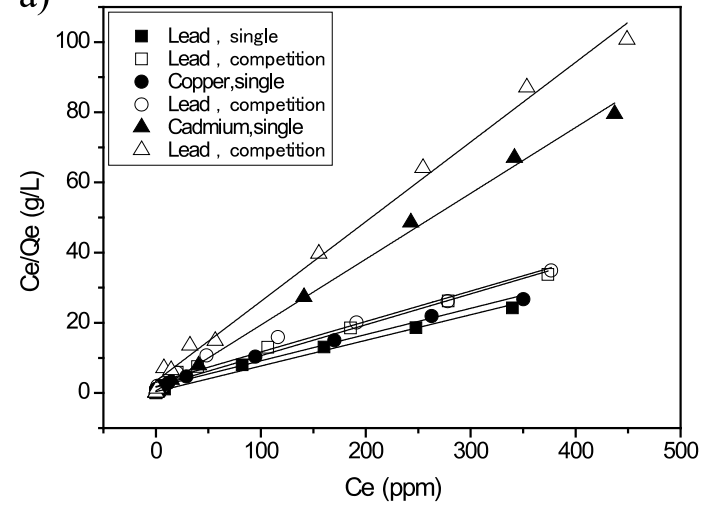

b)

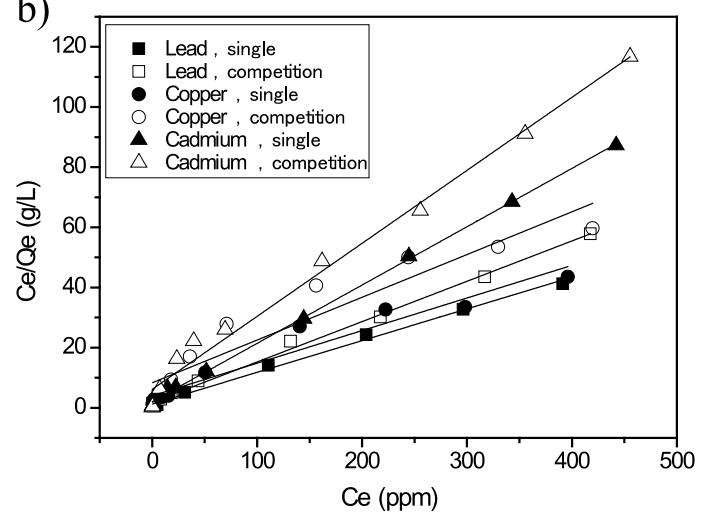

c)

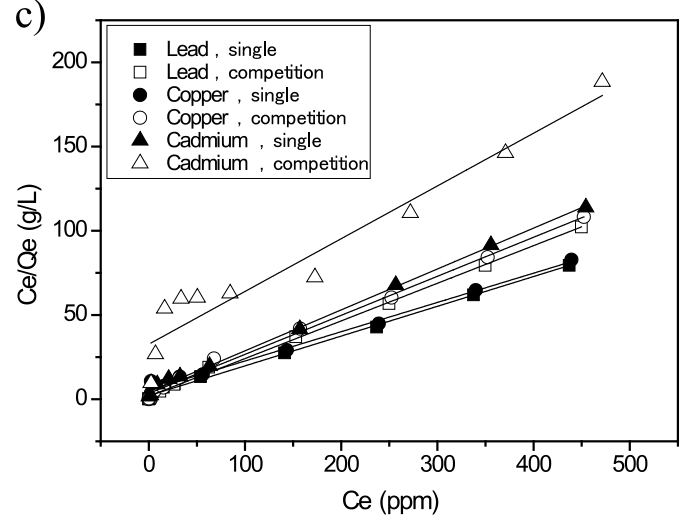

Fig. 7. Plot of Langmuir isotherm model fitting for heavy metal ions adsorption by activated carbon, peanut shell and sawdust in single and competition systems: a) activated carbon, b) peanut shell, c) sawdust.

adsorption efficiency for lead, then copper, and their worst efficiency was that measured for cadmium in both single and competitive systems. In a competitive system, each heavy metal ion's adsorption can be suppressed by other kinds of heavy metal ions. According to Table 5, the sum of three heavy metal ion evaluation ratios in the same competitive system was much greater than 1 . This can indicate that, although each heavy metal ion was less well adsorbed in a competitive system, the total heavy metal ion adsorption increased compared with that in a single system. Thus, the effect of mixing heavy metal ions in a competitive system was antagonistic, but the degree of suppression therein was not very strong
[47]. In other research, heavy metal ion adsorption decreased in multiple metal systems, which was similar to the results of this study $[45,46]$.

\section{Conclusions}

The adsorption characteristics of heavy metal ions by activated carbon, peanut shell, and sawdust were investigated in single and competitive systems. Adsorption efficiencies in descending order for different kinds of heavy metal ions is: lead, copper, cadmium. FTIR results indicate different functional groups for different adsorbents, thus the adsorbents show different adsorption capacities for heavy metal ions; the adsorption efficiency of different adsorbents was ranked (in descending order) as: activated carbon, peanut shell, sawdust. The amount of heavy metal ions adsorbed increased with increasing adsorption times; as the initial concentration of heavy metal ions increased, the amount of heavy metal ions adsorbed also increased, while the removal ratio decreased; the adsorption process followed the Langmuir isotherm model and pseudo second-order kinetic model; there were antagonistic effects among the three kinds of heavy metal ions in a competitive system, as evinced by the adsorption results.

In conclusion, as an agricultural waste material, peanut shell is a potential adsorbent for heavy metal removal with good adsorption efficiency, however, there are some limitations to this study: other factors that can influence the adsorption efficiency should be taken into consideration, including $\mathrm{pH}$ value and temperature; and large-scale simulation experiments should be conducted in order to improve understanding of their adsorption efficiency of adsorbent in field application.

\section{Acknowledgements}

This study was financially supported by the National Natural Science Foundation of China (51978438), Shanxi Scholarship Council of China (2017-039), Scientific Research Foundation of Shanxi Province of China (201701D121121), Korea Ministry of Environment as "The $\operatorname{SEM(Subsurface~Environment~Management)~}$ projects; 2019 ", China Scholarship Council.

\section{Conflict of Interest}

The authors declare no conflict of interest.

\section{References}

1. ZHOU G., LUO J., LIU C., CHU L., CRITTENDEN J. Efficient heavy metal removal from industrial melting effluent using fixed-bed process based on porous hydrogel adsorbents. Water research, 131, 246. 2018. 
2. DEMEY H., VINCENT T., GUIBAL E. A novel algalbased sorbent for heavy metal removal. Chemical Engineering Journal, 332, 582, 2018.

3. BURAKOV A.E., GALUNIN E.V., BURAKOVA I.V., KUCHEROVA A.E., AGARWAL S., TKACHEV, A.G., GUPTA, V.K. Adsorption of heavy metals on conventional and nanostructured materials for wastewater treatment purposes: A review. Ecotoxicology and environmental safety, 148, 702, 2018.

4. JAISHANKAR M., TSETEN T., ANBALAGAN N., MATHEW B.B., BEEREGOWDA, K.N. Toxicity, mechanism and health effects of some heavy metals. Interdisciplinary toxicology, 7 (2), 60, 2014.

5. LIU Y., XIAO T., BAVEYE P.C., ZHU J., NING Z., LI $\mathrm{H}$. Potential health risk in areas with high naturallyoccurring cadmium background in southwestern China. Ecotoxicology and environmental safety, 112, 122, 2015.

6. LIU X., ZHONG L., MENG J., WANG F., ZHANG J., ZHI Y., ZENG L., TANG X., XU J. A multi-medium chain modeling approach to estimate the cumulative effects of cadmium pollution on human health. Environmental Pollution, 239, 308, 2018.

7. WU W., WU P., YANG F., SUN D.L., ZHANG D.X., ZHOU Y.K. Assessment of heavy metal pollution and human health risks in urban soils around an electronics manufacturing facility. Science of The Total Environment, 630, 53, 2018.

8. LU D., HUANG Q., DENG C., ZHENG Y. Phytoremediation of Copper Pollution by Eight Aquatic Plants. Polish Journal of Environmental Studies, 27 (1), 175, 2018

9. FU F., WANG Q. Removal of heavy metal ions from wastewaters: a review. Journal of environmental management, 92 (3), 407, 2011.

10. ZHOU G., LUO J., LIU C., CHU L., CRITTENDEN J. Efficient heavy metal removal from industrial melting effluent using fixed-bed process based on porous hydrogel adsorbents. Water research, 131, 246, 2018.

11. LEGROURI K., KHOUYA E., HANNACHE H., EL HARTTI M., EZZINE M., NASLAIN R. Activated carbon from molasses efficiency for $\mathrm{Cr}$ (VI), $\mathrm{Pb}$ (II) and $\mathrm{Cu}$ (II) adsorption: a mechanistic study. Chemistry International, 3 (3), 301, 2017.

12. CRINI G., LICHTFOUSE E., WILSON L. D., MORINCRINI N. Adsorption-Oriented Processes Using Conventional and Non-conventional Adsorbents for Wastewater Treatment. Green Adsorbents for Pollutant Removal; Crini G, Lichtfouse E, Eds., Springer: Cham, Volume 18, 23, 2018.

13. ALI R.M., HAMAD H.A., HUSSEIN M.M., MALASH G.F. Potential of using green adsorbent of heavy metal removal from aqueous solutions: adsorption kinetics, isotherm, thermodynamic, mechanism and economic analysis. Ecological Engineering, 91, 317, 2016.

14. SADEEK S.A., NEGM N.A., HEFNI H.H., WAHAB M.M.A. Metal adsorption by agricultural biosorbents: Adsorption isotherm, kinetic and biosorbents chemical structures. International journal of biological macromolecules, 81, 400, 2015.

15. DEMIRBAS A. Heavy metal adsorption onto agrobased waste materials: a review. Journal of hazardous materials, 157 (2-3), 220, 2008.

16. CUIPING L., CHUANGZHI W., HAITAO H. Study on the distribution and quantity of biomass residues resource in China. Biomass and bioenergy, 27 (2), 111, 2004.
17. HAO L., ZHENG T., JIANG J., ZHANG G., WANG P. Removal of As (III) and As (V) from water using iron doped amino functionalized sawdust: characterization, adsorptive performance and UF membrane separation. Chemical Engineering Journal, 292, 163, 2016.

18. BILIR M.H., ŞAKALAR N., ACEMIOĞLU B., BARAN E., ALMA M.H. Sorption of remazol brilliant blue $r$ onto polyurethane-type foam prepared from peanut shell. Journal of Applied Polymer Science, 127, 4340, 2013.

19. XU T., LIU X.Q. Peanut shell activated carbon: characterization, surface modification and adsorption of $\mathrm{Pb}^{2+}$ from aqueous solution. Chinese Journal of Chemical Engineering, 16 (3), 401, 2008.

20. ÜNLÜ N., ERSOZ M. Adsorption characteristics of heavy metal ions onto a low cost biopolymeric sorbent from aqueous solutions. Journal of Hazardous Materials, 136 (2), 272-280, 2006

21. YU B., ZHANG Y., SHUKLA A., SHUKLA S.S., DORRIS K.L. The removal of heavy metal from aqueous solutions by sawdust adsorption-removal of copper. Journal of Hazardous Materials, 80 (1-3), 33, 2000.

22. GUPTA S., KUMAR D., GAUR J.P. Kinetic and isotherm modeling of lead (II) sorption onto some waste plant materials. Chemical Engineering Journal, 148 (2-3), 226, 2009.

23. WITEK-KROWIAK A., SZAFRAN R.G., MODELSKI S. Biosorption of heavy metals from aqueous solutions onto peanut shell as a low-cost biosorbent. Desalination, 265 (13), 126, 2011.

24. BULUT Y., TEZ Z. Removal of heavy metals from aqueous solution by sawdust adsorption. Journal of Environmental Sciences(China), 19 (2), 160, 2007.

25. ŠĆIBAN M., RADETIĆ B., KEVREŠAN Ž., KLAŠNJA M. Adsorption of heavy metals from electroplating wastewater by wood sawdust. Bioresource Technology, 98 (2), 402, 2007.

26. YU L.J., SHUKLA S.S., DORRIS K.L., SHUKLA A., MARGRAVE J.L. Adsorption of chromium from aqueous solutions by maple sawdust. Journal of hazardous materials, 100 (1-3), 53, 2003.

27. BOŽIĆ D., STANKOVIĆ V., GORGIEVSKI M., BOGDANOVIĆ G., KOVAČEVIĆ R. Adsorption of heavy metal ions by sawdust of deciduous trees. Journal of hazardous materials, 171 (1-3), 684, 2009.

28. BOHLI T., OUEDERNI A., FIOL N., VILLAESCUSA I. Evaluation of an activated carbon from olive stones used as an adsorbent for heavy metal removal from aqueous phases. Comptes rendus chimie, 18 (1), 88, 2015.

29. WANG F., PAN Y., CAI P., GUO T., XIAO H. Single and binary adsorption of heavy metal ions from aqueous solutions using sugarcane cellulose-based adsorbent. Bioresource technology, 241, 482, 2017.

30. PARK J.H., OK Y.S., KIM S.H., CHO J.S., HEO J.S., DELAUNE R.D., SEO D.C. Competitive adsorption of heavy metals onto sesame straw biochar in aqueous solutions. Chemosphere, 142, 77, 2016.

31. FANG L., LI L., QU Z., XU H., XU J., YAN N. (2018). A novel method for the sequential removal and separation of multiple heavy metals from wastewater. Journal of hazardous materials, 342, 617, 2018

32. LI Y.H., DING J., LUAN Z., DI Z., ZHU Y., XU C., WU D., WEI B. Competitive adsorption of $\mathrm{Pb}^{2+}, \mathrm{Cu}^{2+}$ and $\mathrm{Cd}^{2+}$ ions from aqueous solutions by multiwalled carbon nanotubes. Carbon, 41 (14), 2787, 2003. 
33. PRELOT B., ARAÏSSI M., GRAS P., MARCHANDEAU F., ZAJAC J. Contribution of calorimetry to the understanding of competitive adsorption of calcium, strontium, barium, and cadmium onto 4A type zeolite from two-metal aqueous solutions. Thermochimica Acta, 664, 39, 2018

34. HE S., LI Y., WENG L., WANG J., HE J., LIU Y., ZHANG K., WU Q., ZHANG Y., ZHANG Z. Competitive adsorption of $\mathrm{Cd}^{2+}, \mathrm{Pb}^{2+}$ and $\mathrm{Ni}^{2+}$ onto $\mathrm{Fe}^{3+}$-modified argillaceous limestone: Influence of $\mathrm{pH}$, ionic strength and natural organic matters. Science of The Total Environment, 637, 69, 2018.

35. SHEN J., HUANG G., AN C., XIN X., HUANG C., ROSENDAHL S. Removal of Tetrabromobisphenol A by adsorption on pinecone-derived activated charcoals: Synchrotron FTIR, kinetics and surface functionality analyses. Bioresource Technology, 247, 812, 2018.

36. KHAN M.A., KHAN S., DING X., KHAN A., ALAM $M$. The effects of biochar and rice husk on adsorption and desorption of cadmium on to soils with different water conditions (upland and saturated). Chemosphere, 193, 1120, 2018.

37. SONG J., ZOU W., BIAN Y., SU F., HAN R. Adsorption characteristics of methylene blue by peanut husk in batch and column modes. Desalination, 265 (1-3), 119, 2018.

38. WAHAB M.A., JELLALI S., JEDIDI N. Ammonium biosorption onto sawdust: FTIR analysis, kinetics and adsorption isotherms modeling. Bioresource Technology, 101 (14), 5070, 2010.

39. SOGUT E.G., CALISKAN N. Iisotherm and kinetic studies of $\mathrm{Pb}$ (ii) adsorption on raw and modified diatomite by using non-linear regression method. Fresenius environmental bulletin, 26 (4), 2720, 2017.
40. WANG J., JI B., SHU Y., CHEN W., ZHU L., CHEN, F. Cr (VI) Removal from Aqueous Solution Using Starch and Sodium Carboxymethyl Cellulose-Coated $\mathrm{Fe}$ and $\mathrm{Fe} / \mathrm{Ni}$ Nanoparticles. Polish Journal of Environmental Studies, 27 (6), 2785, 2018.

41. HO Y.S., MCKAY G. Pseudo-second order model for sorption processes. Process biochemistry, 34 (5), 451, 1999.

42. ZAMRI M.F.M.A., KAMARUDDIN M.A., YUSOFF M.S., AZIZ H.A., FOO K.Y. Semi-aerobic stabilized landfill leachate treatment by ion exchange resin: isotherm and kinetic study. Applied Water Science, 7 (2), 581, 2017.

43. GHASEMI M., NAUSHAD M., GHASEMI N., KHOSRAVI-FARD Y. Adsorption of $\mathrm{Pb}$ (II) from aqueous solution using new adsorbents prepared from agricultural waste: adsorption isotherm and kinetic studies. Journal of Industrial and Engineering Chemistry, 20 (4), 2193, 2014.

44. YI Z.J., YAO J., CHEN H.L., WANG F., YUAN Z.M., LIU X. Uranium biosorption from aqueous solution onto Eichhornia crassipes. Journal of environmental radioactivity, 154, 43, 2016.

45. IQBAL M., KHERA R.A. Adsorption of copper and lead in single and binary metal system onto Fumaria indica biomass. Chemistry International, 1 (3), 157, 2015.

46. MAHAMADI C., NHARINGO T. Competitive adsorption of $\mathrm{Pb}^{2+}, \mathrm{Cd}^{2+}$ and $\mathrm{Zn}^{2+}$ ions onto Eichhornia crassipes in binary and ternary systems. Bioresource Technology, 101 (3), 859, 2010.

47. AGARWAL B., BALOMAJUMDER C., THAKUR P.K. Simultaneous co-adsorptive removal of phenol and cyanide from binary solution using granular activated carbon. Chemical engineering journal, 228, 655, 2013. 
